\title{
ANALISIS EFEKTIVITAS KINERJA KARYAWAN PERUSAHAAN PEMBIAYAAN PT. ADIRA CABANG DENPASAR 1 BERDASARKAN PENGARUH KEPEMIMPINAN DAN LINGKUNGAN KERJA
}

\author{
Ni Wayan Cahya Ayu Pratami \\ Sistem Informasi STMIK STIKOM Bali \\ Email : cahyaayupratami@gmail.com
}

\begin{abstract}
Good human resource management in a company not only imposes leadership power on its employees, but how a leader can also wisely receive complaints or suggestions conveyed by his employees for the common good, so that employees feel at home and comfortable while working improving employee performance is through improvements in leadership and work environment. These improvements are expected to foster job satisfaction for employees. Increased job satisfaction is also expected to have an impact on increasing the performance of employees themselves. Leadership and work environment have an influence on job satisfaction and employee performance in the finance company PT. Adira Denpasar 1 Branch, involving a number of respondents. Respondent data will be processed using the Partial Least Square (PLS) method through the Smart PLS 2.0 M3 program. The results found that leadership has a positive impact on job satisfaction but the relationship does not have a significant effect while the work environment has a significant and positive influence on performance, and job satisfaction has a positive impact on performance but does not have a significant effect. The results of statistical tests that show no significance are caused by indicators of lack of leaders in carrying out their roles in carrying out their duties and ordering their employees to achieve goals.
\end{abstract}

Keywords: employees, leadership, work environment, Partial Least Square.

\section{PENDAHULUAN}

Kebebasan berusaha ini telah menjadi tuntutan dan kebutuhan masyarakat dunia dari strata manapun mereka berada. Dengan demikian, dalam era persaingan bebas ini peran pemerintah semakin berkurang terutama dalam perekonomian dengan berbagai proteksi baik pada badan usaha milik swasta maupun badan usaha milik negara. Persaingan global yang diawali pada abad millenium yang secara bertahap mulai dilaksanakan pada 
permulaan abad ke-21 pada negara-negara kawasan Asia Tenggara, Asia Pasifik sampai akhirnya dapat diberlakukan secara internasional. Pelaksanaan era tanpa batas ini telah disepakati oleh para pemimpin negara maju dan negara berkembang termasuk Indonesia.

Salah satu persoalan penting yang perlu diperbaiki adalah kualitas sumber daya manusia, baik secara mikro yaitu perbaikan manajemen SDM dalam perusahaan serta secara makro yaitu perbaikan angkatan kerja dalam skala nasional. Alasan utama perbaikan kualitas SDM dalam perusahaan terutama karena peran strategis SDM sebagai pelaksana dari fungsi-fungsi perusahaan. Perusahaan-perusahaan menghadapi tantangan untuk mampu meningkatkan kualitas sumber daya manusia agar memiliki keahlian khusus sehingga mampu bersaing dengan dunia usaha.

Manajemen sumber daya manusia yang baik dalam sebuah perusahaan tidak hanya memaksakan kekuasaan pimpinan kepada para karyawannya saja, tetapi bagaimana seorang pemimpin dapat juga secara bijak menerima keluhan ataupun saran yang disampaikan oleh para karyawannya demi kepentingan bersama, sehingga para karyawan merasa betah dan nyaman selama bekerja. Keseimbangan manajemen sumber daya manusia ini akan menciptakan suasana yang kondusif di tempat kerja, sehingga dapat menciptakan kinerja atau prestasi kerja para karyawan secara terus menerus. Dalam memimpin sebuah perusahaan, kinerja karyawan menjadi sangat penting karena merupakan tolak ukur keberhasilan dalam mengelola perusahaan. Jadi kinerja merupakan faktor sentral bagi manajemen sehingga perlu untuk memahami dan mengenali berbagai aspek yang berkaitan dengan kinerja karyawan.

Rendahnya kinerja karyawan bukan hanya kesalahan karyawan semata, perusahaan tidak hanya melihat dari aspek kesalahan atau pelanggaran yang dilakukan karyawan saja 
melainkan juga harus dilihat dari apakah perusahaan sudah melihat dan menanggapi keluhan yang disampaikan oleh karyawannya, sebab dengan tanpa menyeimbangkan kepentingan kedua belah pihak dimana perusahaan memandang tujuan organisasi adalah sebagai sesuatu yang sangat penting untuk dicapai, sementara disisi lain karyawan memandang perhatian terhadap keluhannya sebagai sesuatu yang penting pula, maka apa yang menjadi sasaran perusahaan secara keseluruhan, dalam hal ini adalah kinerja/prestasi kerja yang baik sulit diwujudkan.

PT Adira Cabang Denpasar 1 resmi dibuka pada tanggal 15 Mei 2000 dengan awalnya hanya terdiri dari 15 karyawan yang dipimpin oleh seorang Branch Manager. Seiring berjalannya waktu PT Adira Cabang Denpasar 1 pada tahun 2016 telah memiliki karyawan sebanyak 187 karyawan yang dipimpin oleh seorang Branch Manager dan seorang Deputy Branch Manager.

Banyak penelitian telah dilakukan untuk mengetahui faktor yang mempengaruhi tingkat kepuasan kerja karyawan pada perusahaan, misalnya: gaji, pekerjaan, pimpinan, rekan kerja, dan situasi kerja (Yuliastuti dan Bimowati, 2009), dan ada juga dari faktor kepemimpinan serta komunikasi (Gunawan, 2011). Berdasarkan uraian fenomena diatas, maka menarik untuk dilakukan penelitian mengenai kinerja karyawan perusahaan pembiayaan PT. Adira cabang Denpasar 1, berdasarkan pengaruh kepemimpinan dan lingkungan kerja.

Batasan masalah penelitian ini hanya mencakup tentang analisis tentang hubungan dan juga pengaruh dari masing-masing variabel, yaitu: hubungan kepemimpinan terhadap kepuasan karyawan, hubungan lingkungan kerja terhadap kepuasan kerja, hubungan kepemimpinan terhadap kinerja karyawan, hubungan lingkungan kerja terhadap kinerja 
karyawan, dan hubungan kepuasan kerja terhadap kinerja karyawan di PT. Adira cabang Denpasar 1. Tujuan penelitian dampak atau pengaruh kinerja karyawan perusahaan pembiayaan PT. Adira cabang Denpasar 1 berdasarkan kepemimpinan dan lingkungan kerja.

Menurut Saari dan Judge dalam Dharmanegara (2016) menunjukkan bahwa kepuasan kerja mempunyai hubungan yang positif dan signifikan dengan kinerja karyawan. Khan et al. (2012) dalam penelitiannya menyebutkan bahwa aspek kepuasan kerja seperti gaji, promosi, keselamatan kerja dan keamanan, kondisi kerja, otonomi pekerjaan, hubungan dengan rekan kerja, hubungan dengan atasan, dan sifat pekerjaan secara signifikan mempengaruhi tingkat kepuasan kerja. Untuk meningkatkan kinerja karyawan di lembaga medis otonom, pemerintah harus fokus menghadapi semua faktorfaktor kepuasan kerja dan tidak hanya fokus pada salah satu faktor ini (promosi, kondisi kerja, rekan kerja, dan sifat pekerjaan yang memiliki dampak yang signifikan terhadap tingkat kepuasan kerja).

Dalam penelitian yang dilakukan oleh Gardjito, dkk.(2014), menunjukkan bahwa lingkungan kerja berpengaruh signifikan terhadap kinerja karyawan PT. Karmand Mitra Andalan Surabaya. Penelitian yang dilakukan oleh Imran, et al. (2012), menunjukan pengaruh positif dan signifikan kepemimpinan tranformasional dan lingkungan kerja terhadap kinerja karyawan. Penelitian lain yang dilakukan Nursasongko (2012) yang menyatakan bahwa kepemimpinan, lingkungan kerja, dan kompensasi secara simultan berpengaruh signifikan terhadap kinerja karyawan negeri sipil di lingkungan pemerintah Kabupaten Pemalang. Penelitian Cahyani dan Ardana (2013) menunjukkan bahwa penataan ruang yang tepat pada tempat kerja akan berpengaruh terhadap kinerja karyawan. 
Penataan ruang ini harus didukung dengan distribusi cahaya yang cukup, pemilihan warna dinding yang tepat, sirkulasi udara dan suhu udara sesuai dengan ruangan (Norianggono, Hamid dan Ruhana, 2014).

\section{Kepemimpinan}

Kepemimpinan adalah kemampuan untuk mempengaruhi orang lain dengan rasa semangat demi tercapainya tujuan yang telah ditentukan (Davis dan Newstrom, 2008). Kepemimpinan tidak hanya menyangkut kemampuan mempengaruhi orang lain secara individu saja, tetapi juga beberapa orang atau kelompok. Kepemimpinan dalam ruang lingkup kelompok adalah yang sesuai dengan prinsip kepemimpinan sebuah perusahaan, yaitu bagaimana individu-individu dalam sebuah kelompok dapat saling bekerjasama satu sama lain secara teratur dan terkoordinasi dengan baik di bawah satu kepemimpinan. Hubungan yang baik diantara individu tersebut hendaknya tetap dijaga untuk tetap solid dan kompak, begitu juga halnya dengan hubungan baik antara individu dengan pimpinan. Kepemimpinan ini mempunyai pengaruh positif terhadap kepuasan kerja dan juga kinerja karyawan di sebuah perusahaan, karena semakin baik kepemimpinan semakin tinggi pula kepuasan kerja karyawan dan semakin baik pula kinerja para karyawan.

\section{Kinerja Karyawan}

Kinerja mempunyai makna yang luas bukan hanya menyatakan sebagai hasil kerja tetapi juga bagaimana proses kerja berlangsung. Kinerja merupakan perilaku nyata yang ditampilkan setiap orang sebagai prestasi kerja yang dihasilkan oleh karyawan sesuai dengan perannya dalam perusahaan. Kinerja karyawan merupakan suatu hal yang sangat penting dalam upaya perusahaan untuk mencapai tujuannya. Kondisi yang harus diketahui dan diinformasikan kepada pihak-pihak tertentu untuk mengetahui tingkat pencapaian hasil 
suatu perusahaan dihubungkan dengan visi yang diemban suatu perusahaan serta mengetahui dampak positif dan negatif suatu kebijakan operasional yang diambil.Mathis dan Jackson (2002) menyatakan bahwa kinerja pada dasarnya adalah apa yang dilakukan atau tidak dilakukan karyawan. Manajemen kinerja adalah keseluruhan kegiatan yang dilakukan untuk meningkatkan kinerja perusahaan atau organisasi, termasuk kinerja masing-masing individu dan kelompok kerja di perusahaan tersebut. Rumusan permasalahan dalam penelitian ini berdasarkan uraian latar belakang masalah tersebut adalah sebagai berikut:

1. Bagaimanakah pengaruh kepemimpinan terhadap kepuasan kerja karyawan?

2. Bagaimanakah pengaruh lingkungan kerja terhadap kepuasan kerja karyawan?

3. Bagaimanakah pengaruh kepemimpinan terhadap kinerja karyawan?

4. Bagaimanakah pengaruh lingkungan kerja terhadap kinerja karyawan?

5. Bagaimanakah pengaruh kepuasan kerja terhadap kinerja karyawan?

\section{Pengukuran Kinerja}

Tidak semua kriteria pengukuran kinerja dapat dipakai dalam penilaian kinerja karyawan, tentu hal ini harus disesuaikan dengan jenis pekerjaan yang akan dinilai. Menurut Mahmudi (2005) tiga variabel penting yang harus dipertimbangkan dalam pengukuran kinerja yaitu pelaku (input), perilaku (proses), dan hasil kerja (output),

1. Kinerja berbasis pelaku

Lebih menekankan pada pegawai pelaksana kinerja, penilaian kinerja difokuskan pada pelaku dengan atribut-atribut, karakteristik dan kualitas personal yang dipandang sebagai faktor utama kinerja.

2. Kinerja berbasis perilaku 
Tidak semata-mata berfokus pada faktor pegawai namun berkonsentrasi pada perilaku yang dilakukan seseorang dalam melakukan kerja.

3. Kinerja berbasis hasil kerja

Kinerja berbasis hasil kerja difokuskan pada hasil, selain memfokuskan pada hasil juga harus tetap memperhatikan faktor perilaku dan kualitas personal.

\section{Partial Least Square (PLS)}

Ghozali (2013) menjelaskan bahwa PLS adalah metode analisis yang bersifat soft modeling karena tidak mengasumsikan data harus dengan pengukuran skala tertentu, yang berarti jumlah sampel dapat kecil (dibawah 100 sampel). Perbedaan mendasar PLS yang merupakan SEM berbasis varian dengan LISREL atau AMOS yang berbasis kovarian adalah tujuan penggunaannya. Menurut Jaya dan Sumertajaya (2008) langkah-langkah dalam penggunaan Partial Least Square yang lazim dilakukan adalah sebagai berikut (gambar 1).

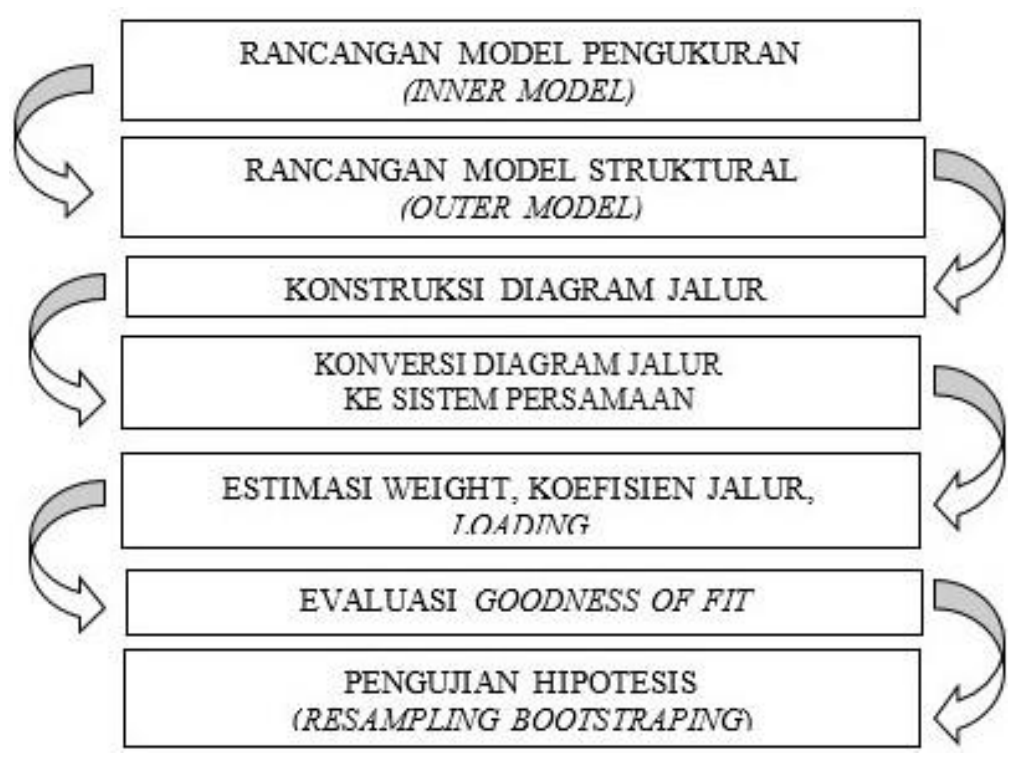

Gambar 1. Tahapan Analisis Partial Least Square (PLS) 


\section{METODE PENELITIAN}

Penelitian ini menggunakan desain kuantitatif dengan memfokuskan para karyawan yang bekerja langsung di tempat penelitian. Penyebaran angket dilakukan untuk mendapatkan data, yang kemudian diolah menggunakan metode pengolahan statistik yaitu metode partial least square (PLS). Penelitian ini merupakan jenis penelitian kausalitas dengan tingkat eksplanasi asosiatif, yaitu penelitian yang mencari hubungan-hubungan dan juga pengaruh antara variabel eksogenous dengan variabel endogenous. Adapun tahapan atau sistematika penelitian dilakukan ditunjukkan pada gambar 2.

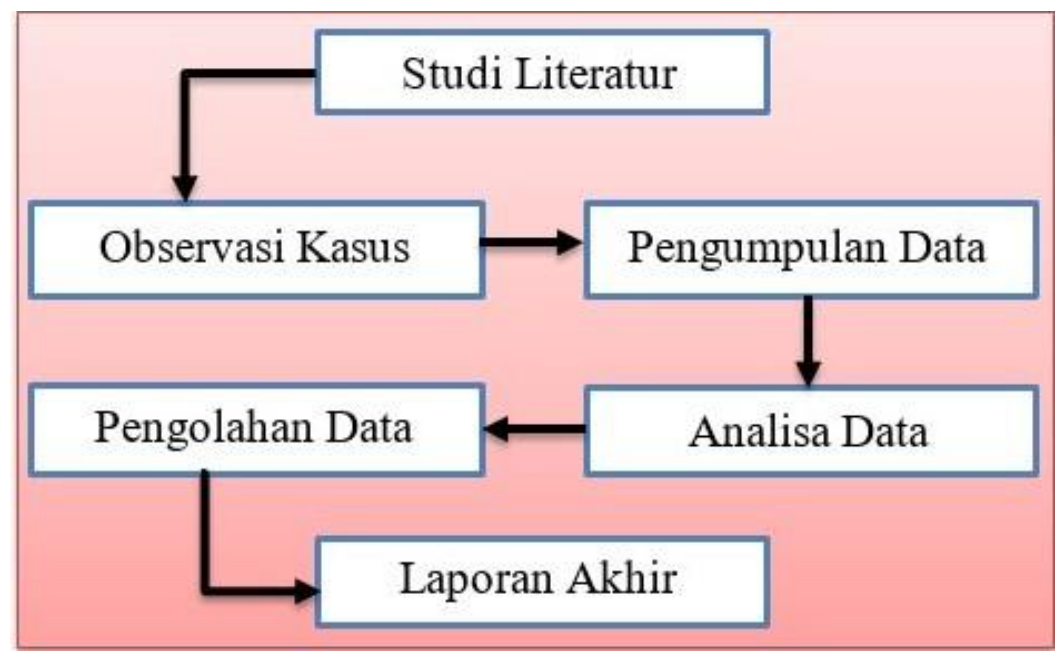

Gambar 2. Sistematika penelitian

Jenis dan sumber data yang dipergunakan dalam penelitian ini dapat dibedakan menjadi dua yaitu: data primer dan data sekunder. Data primer dalam penelitian ini adalah tanggapan responden terhadap pernyataan-pernyataan yang terdapat pada angket yang dibagikan kepada karyawan. Data sekunder dalam penelitian ini meliputi jumlah karyawan, pencapaian hasil kerja karyawan dalam 1 tahun dan informasi lain yang didapat dari lokasi penelitian. Teknik analisis yang digunakan dalam penelitian ini ada dua jenis, yaitu: 
analisis deskriptif dan analisis inferensial. Analisis Deskriptif yang dipergunakan dalam penelitian ini adalah untuk menggambarkan karakteristik responden penelitian dilihat dari beberapa variable penelitian yang menyangkut: persepsi responden terhadap kepemimpinan, lingkungan kerja, kepuasan kerja dan kinerjanya. Analisis Inferensial dipergunakan untuk menganalisis

\section{HASIL PENELITIAN DAN PEMBAHASAN}

\section{Tahapan Analisis Partial Least Square (PLS)}

Diagram alur tampak seperti Gambar 3 yaitu Hierarki Model Partial Least Square (PLS) untuk kasus menganalisis pengaruh antara variable eksogen dengan variable endogen.

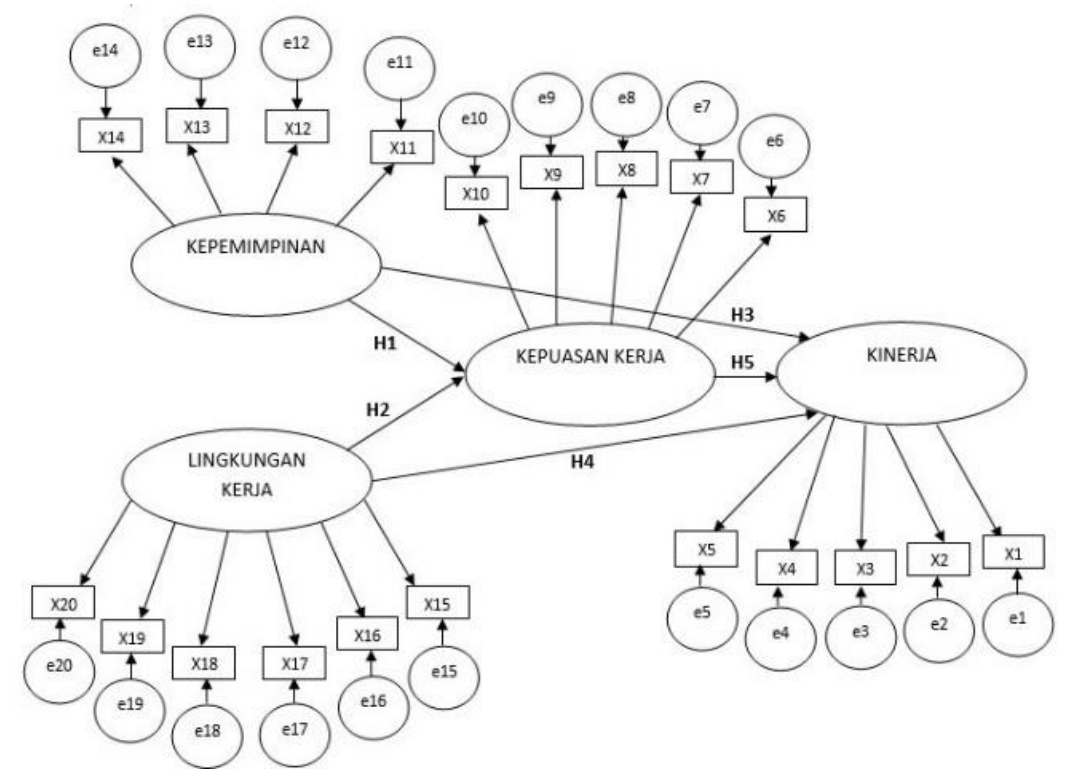

Gambar 3. Hierarki Model Partial Least Square (PLS)

\section{Karakteristik Responden}

Berdasarkan hasil pengumpulan data dan analisis karakteristik responden penelitian maka dapat dikelompokkan menjadi beberapa kelompok, yaitu pengelompokkan menurut jenis kelamin, umur, tingkat pendidikan dan masa kerja pada PT. Adira cabang Denpasar. 


\section{Deskripsi Variabel Kepemimpinan}

Variabel kepemimpinan dalam penelitian ini terdiri dari 4 (empat) indikator sebagai dasar pengukurannya, yaitu : pemimpin mampu menerapkan peranannya dalam melakukan suatu tugas dan memerintahkan karyawannya untuk mencapai tujuan; pemimpin selalu memberikan bimbingan, dorongan, arahan yang bersifat supportif dan mampu memberikan ide-ide; pemimpin memiliki hubungan yang baik dengan karyawan; pemimpin dapat mendelegasikan wewenang dengan baik dan tepat.

\section{Uji Validitas}

Uji validitas digunakan untuk mengetahui apakah setiap butir pernyataan dalam angket (instrumen yang digunakan) valid. Setelah dilakukan proses validasi, diperoleh hasil bahwa seluruh item pernyataan pada masing-masing indikator adalah valid, karena memiliki nilai koefisien korelasi > 0,30 sebagaimana yang ditunjukkan dalam tabel dibawah ini.

Tabel 1. Uji Validitas

\begin{tabular}{lcl}
\hline \multicolumn{1}{c}{ Indikator/Konstruk } & Nilai Korelasi & Keterangan \\
\hline Kepemimpinan : & 0,943 & Valid \\
X11 & 0,960 & Valid \\
X12 & 0,912 & Valid \\
X13 & 0,977 & Valid \\
X14 & & \\
Lingkungan Kerja : & 0,838 & Valid \\
X21 & 0,591 & Valid \\
X22 & 0,760 & Valid \\
X23 & 0,870 & Valid \\
X24 & 0,798 & Valid \\
X25 & 0,769 & Valid \\
X26 & & \\
\hline
\end{tabular}




\begin{tabular}{lll}
\hline Kepuasan Kerja : & & \\
Y11 & 0,787 & Valid \\
Y12 & 0,839 & Valid \\
Y13 & 0,693 & Valid \\
Y14 & 0,860 & Valid \\
Y15 & 0,783 & Valid \\
Kinerja : & & \\
Y21 & 0,891 & Valid \\
Y22 & 0,908 & Valid \\
Y23 & 0,787 & Valid \\
Y24 & 0,844 & Valid \\
Y25 & 0,811 & Valid \\
\hline
\end{tabular}

Berdasarkan hasil Tabel 1 hasil koefisien korelasi dari kepemimpinan X11 sebesar 0,943; X12 sebesar 0,960; X13 sebesar 0,912; X14 sebesar 0,977. Setiap pernyataan nilai koefisien korelasinya $>0,30$ sehingga semua pernyataan adalah valid dengan kriteria uji validitas baik.

Hasil koefisien korelasi dari lingkungan kerja X21 sebesar 0,838; X22 sebesar 0,591; X23 sebesar 0,760; X24 sebesar 0,870 ; X25 sebesar 0,798; X26 sebesar 0,769. Setiap pernyataan nilai koefisien korelasinya $>0,30$ sehingga semua pernyataan adalah valid dengan kriteria uji validitas baik.

\section{Uji Reliabilitas}

Uji reliabilitas digunakan untuk mengetahui apakah instrumen dapat dipercaya, handal dan akurat. Pengujian reliabilitas dalam penelitian ini menggunakan formula koefisien Alpha Cronbach. Konstruk dikatakan reliabel jika nilai Cronbach Alpha based on Standardized Items $>0,60$. 
Tabel 2. Uji Reliabilitas

\begin{tabular}{lcc}
\hline \multicolumn{1}{c}{ Indikator/Konstruk } & Koefisien Alpha Cronbach & Keterangan \\
\hline Kepemimpinan & 0,962 & Reliabel \\
Lingkungan Kerja & 0,866 & Reliabel \\
Kepuasan Kerja & 0,859 & Reliabel \\
Kinerja & 0,903 & Reliabel \\
\hline
\end{tabular}

Hasil uji reliabilitas kepemimpinan (X1) pada Tabel 2, Cronbach Alpha Based on Standardized Items sebesar 0,962. Nilai Cronbach Alpha Based on Standardized Items > 0,60 sehingga konstruk kepemimpinan adalah reliabel dengan kriteria uji reliabilitas baik.

\section{SIMPULAN}

Simpulan yang diperoleh dari hasil analisis data menunjukkan bahwa kepemimpinan berpengaruh positif namun tidak signifikan terhadap kepuasan kerja. Hal ini menunjukkan bahwa kepemimpinan yang memiliki karakteristik, antara lain mampu menerapkan peranannya dalam melakukan suatu tugas dan memerintahkan karyawannya untuk mencapai tujuan, selalu memberikan bimbingan, dorongan, arahan yang bersifat supportif dan mampu memberikan ide-ide, memiliki hubungan yang baik dengan karyawan, dapat mendelegasikan wewenang dengan baik dan tepat dapat meningkatkan kepuasan kerja karyawan. Kepuasan kerja berpengaruh positif namun tidak signifikan terhadap kinerja. Hal ini menunjukkan bahwa karyawan mampu menyelesaikan setiap pekerjaan, karyawan dapat mempertanggungjawabkan setiap pekerjaan yang diberikan, karyawan bekerja sesuai prosedur dan jadwal, karyawan hadir tepat waktu, karyawan mampu bekerjasama dengan semua karyawan. 


\section{DAFTAR PUSTAKA}

Abdillah W, Jogiyanto HM. 2009. Konsep dan Aplikasi PLS (Partial Least Square) Untuk Penelitian Empiris. Badan Penerbit Fakultas Ekonomi dan Bisnis UGM, Yogyakarta.

Agastia,A. 2014. Pengaruh Lingkungan Kerja Fisik, Komunikasi dan Kepemimpinan Terhadap Kinerja Karyawan PT. BPR Merta Sedana Badung. E-journal Manajemen Universitas Udayana, 3(1), 29-44

Aldo Herlambang Gardjito, Mochammad Al Musadieg, Gunawan Eko Nurtjahjono. 2014. Pengaruh Motivasi Kerja dan Lingkungan Kerja Terhadap Kinerja Karyawan (Studi Pada Karyawan Bagian Produksi PT. Karmand Mitra Andalan Surabaya). Jurnal Administrasi Bisnis (JAB) Vol.13 No.1 Agustus 2014.

Azeem, Syed Mohammad. 2010. Job Satisfaction and Organizational Commitment among Employees in the Sultanate of Oman, Scientific Research, Vol 1. pp 295 - 299

Cahyani, N.,Ardana,K. 2013. Pengaruh Lingkungan Kerja Fisik, Gaya Kepemimpinan dan Insentif Financial Terhadap Kinerja Pegawai Non Medis Pada Rumah Sakit Balimed Denpasar. E-journal Manajemen Universitas Udayana, 2 (4) , 423-435.

Darmawan, H. 2013. Prinsip-prinsip Perilaku Organisasi. Surabaya : Pena Semesta

Darendehe. Albert. 2013. "Gaji, Kepemimpinan, dan Sikap Rekan Kerja Pengaruhnya Terhadap Kinerja Karyawan PT.Askes (Persero) Cabang Manado”. Jurnal EMBA, Vol.1, No.4.

Dharmanegara, I.B.Agung. Sitiari, Ni Wayan.Wirayudha, I. Dw. Gd.Ngurah. 2016. Job Competency And Work Environtment : The Effect On Job Satisfaction And Job Performance Among SMEs Worker. e-ISSN: 2278-487X, p-ISSN : 2319-7668. Vol.18, Issue 1.Ver.II (Jan 2016).PP 19-26.

Ghozali, Imam. 2013. Aplikasi Analisis Multivariate dengan Program SPSS. Edisi Ketujuh, Semarang : Badan Penerbit Universitas Diponegoro. 